\title{
Carotid shunt provides cerebral protection during emergency coronary artery bypass grafting in a patient with bilateral high grade carotid stenosis: a case report
}

\author{
John K Bellos ${ }^{1 *}$, Nektarios Kogerakis ${ }^{2}$, Charalampos Kiriazis ${ }^{2}$, Alexandros Gougoulakis ${ }^{1}$, Matthew Panagiotou ${ }^{2}$
}

\begin{abstract}
Background: Management of patients with co-existent coronary and carotid disease is a controversial and challenging issue. The risk for stroke after coronary artery bypass grafting (CABG) in patients with hemodynamically significant carotid stenosis is up to $30 \%$. In these patients a common practice is to proceed first with the restoration of cerebral perfusion and then perform the coronary revascularization. The rationale is that this strategy will reduce perioperative neurological morbidity and mortality. However, what happens when the carotid procedure is acutely complicated by cardiac instability which necessitates the interruption of the carotid procedure?

Case report: We describe a case of a patient with unstable angina and high grade asymptomatic bilateral carotid stenosis who underwent emergency combined CABG and carotid endarterectomy (CEA). Due to hemodynamic instability, ST-T changes, hypotension and bradycardia, upon completion of endarterectomy we placed a carotid shunt and the patient was put on cardiopulmonary bypass through median sternotomy. After triple CABG (duration of 90 minutes) we concluded the interrupted CEA procedure with primary closure of the carotid arteriotomy with the shunt in place. The postoperative course was uneventful and the patient was discharged after a week. In extreme cases with bilateral severe carotid stenosis and coronary artery disease where the carotid procedure should be interrupted, we suggest the use of carotid shunt which can provide adequate cerebral perfusion giving time to cardiac surgeon to perform the life saving cardiac procedure first.
\end{abstract}

\section{Background}

Management of patients with co-existent coronary and carotid disease is a controversial and challenging issue [1]. The risk for stroke after coronary artery bypass grafting (CABG), in patients with hemodynamically significant carotid stenosis is up to $30 \%$ [2]. Therefore, in these patients a common practice is to proceed first with the restoration of cerebral perfusion and then perform the coronary revascularization. The rationale is that this strategy will reduce perioperative neurological morbidity and mortality. However, according to our knowledge, there is no published data concerning

\footnotetext{
* Correspondence: bellosvasc@gmail.com

'Department of Vascular Surgery, Athens Medical Center, 5-7 Distomou St,

15125, Marousi Athens, Greece

Full list of author information is available at the end of the article
}

combined carotid endarterectomy (CEA) and CABG where intraoperatively the carotid procedure was acutely complicated by cardiac instability necessitating the interruption of the carotid procedure. We describe our experience using a temporary carotid shunt in order to maintain cerebral perfusion until CABG was completed and then the operation was concluded with the closure of carotid arteriotomy.

\section{Case presentation}

Patient's history and management

A 80 year old male patient with a history of coronary artery disease (CAD) and severe left ventricular dysfunction was urgently admitted in our institution with unstable angina. Ejection fraction was $20 \%$. Coronary angiography revealed severe triple vessel disease. Moreover, duplex

\section{C) Biomed Central}


ultrasound which was performed urgently in intensive care unit (ICU), showed bilateral severe carotid stenosis (80$90 \%$ stenosis and unstable plaque in the right internal carotid artery and $70-80 \%$ stenosis in the left side). Both vertebral arteries were patent without reverse flow or any significant hemodynamic changes. The patient continued to be in unstable angina, therefore we decided to perform emergency combined surgery without a preoperative angiogram. After induction of general anesthesia the right carotid bifurcation was exposed by a standard lateral approach and simultaneously the left great saphenous vein was harvested. Immediately after the completion of endarterectomy and before starting the closure of arteriotomy the patient became hemodynamic unstable with ST-T changes, bradycardia and hypotension. Under these conditions we decided to interrupt the carotid procedure and place a Javid carotid shunt (Bard Peripheral Vascular Inc, AZ, USA), and immediately proceed with a median sternotomy and cardiopulmonary bypass (CPB) (Figure 1A). We performed an emergency triple CABG with saphenous vein grafts under extracorporeal circulation (ECC) and moderate hypothermia $\left(28^{\circ} \mathrm{C}\right)$. After the patient's weaning from $\mathrm{CPB}$ and his pressure stabilization (90 minutes later) the CEA was completed with primary closure of carotid arteriotomy (Figure 1B). The patient was transferred to the ICU for one day and was discharged on the seventh postoperative day with improved left ventricular function and without neurological complications.

\section{Discussion}

The optimal management of patients with combined carotid and coronary artery disease remains controversial. Various strategies have been proposed such as CEA alone, or CABG alone, or staged CEA and CABG, or staged carotid artery stenting (CAS) and CABG, and simultaneous CEA and CABG, or simultaneous CAS and $C A B G$. In the majority of these approaches the CEA or CAS precedes the CABG because it seems that reduces the perioperative neurological morbidity and mortality. We report a case where the CEA procedure was interrupted by the CABG. The carotid procedure was finished after the completion of the CABG. All these handlings were possible through a temporary carotid shunt which proved sufficient to maintain adequate cerebral perfusion for 90 minutes. To our knowledge prolonged cerebral perfusion through a shunt during on pump emergency CABG in patients with bilateral severe carotid stenosis has not been previously reported.

Besides carotid artery stenosis, other stroke risk factors during $C A B G$, frequently quoted in the literature, are: ascending aortic atherosclerosis, previous stroke or transient ischemic attack, age, hypertension, diabetes, smoking, peripheral vascular disease, left ventricular dysfunction, left main CAD, renal failure, and increased cardiopulmonary bypass time [3]. Our patient had the majority of these risk factors (age, left CAD, heavy smoker in the past, left ventricular dysfunction, peripheral

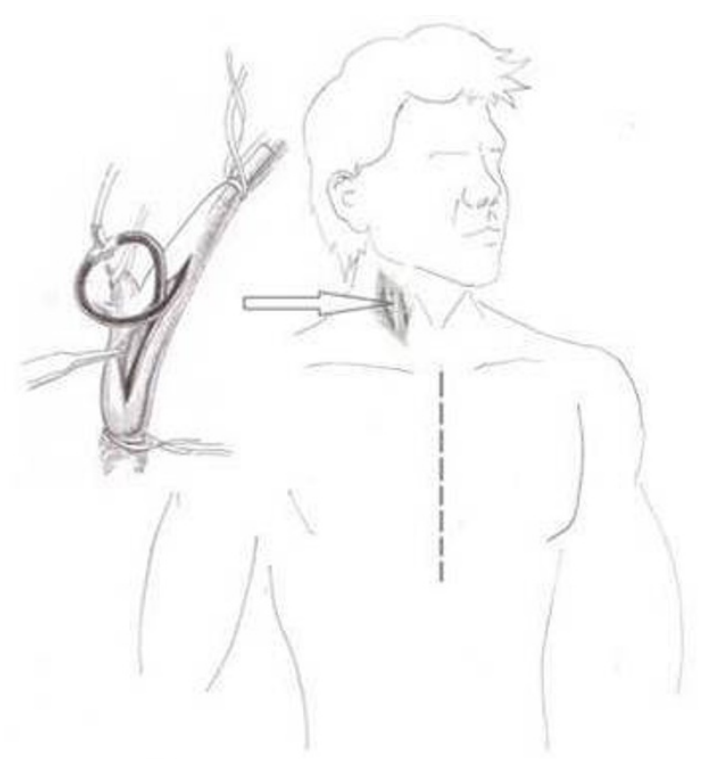

A

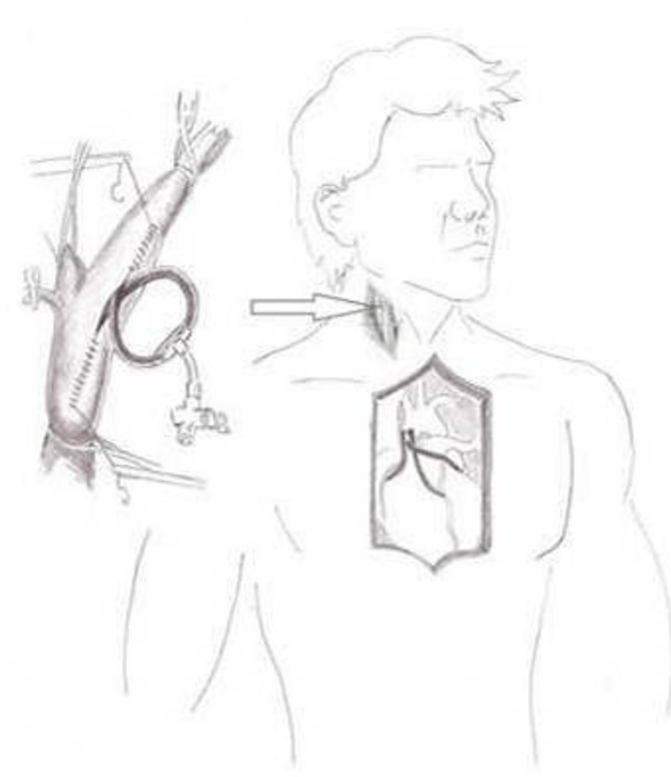

B

Figure 1 Line drawings depict stages of the operative procedure: A) Due to hemodynamic instability we stopped the carotid endarterectomy procedure, we placed a carotid shunt and we proceeded to emergency sternotomy, B) After the completion of 3 coronary artery bypass grafting and patient's weaning from cardiopulmonary bypass, we continued with the primary closure of carotid arteriotomy. 
arterial disease). The only preventive measure against stroke were the carotid shunt, which proved to be adequate, and the patent vertebral arteries.

In a recent case report the authors applied a $14 \mathrm{Fr}$ cannula into the distal part of the internal carotid artery. A separate pump was connected in cannula and arterial blood at $23^{\circ} \mathrm{C}$ was delivered at a flow rate of $300 \mathrm{ml} /$ min [4]. Although, based on classical findings, the normal carotid artery flow rate is $133-200 \mathrm{ml} / \mathrm{min}$, the appropriate flow rate of the active cerebral perfusion is still unclear [5]. However, under CPB the cerebral autoregulation is severely impaired, thus a flow rate of 300 $\mathrm{ml} / \mathrm{min}$ may result to hyperperfusion syndrome and cerebral hemorrhage. Moreover, differences between our technique and the previous mentioned are obvious. Our technique is less complicated, less expensive and less time consuming. Therefore, our report suggests that a carotid shunt could maintain cerebral perfusion and could provide cerebral protection for at least 90 minutes ECC in patient with high grade bilateral carotid stenosis.

Some surgeons prefer the off-pump CABG, especially in patients with severe carotid disease [6]. Off-pump CABG certainly has many advantages and in a recent study an aorto-carotid shunt was used in patients who underwent combined CEA and CABG with satisfactory results [7]. However, in our case this was not feasible because of patient's hemodynamic instability.

Finally, the important role of the shunt in the cerebral perfusion during $\mathrm{CPB}$ is enhanced by the fact that the patient was under diminished systemic pressure, moderate hypothermia and non pulsatile cerebral perfusion from the pump for 90 minutes.

\section{Conclusion}

This case highlights the value of conventional carotid shunt to maintain intra-operative cerebral perfusion during emergency CABG in unstable patients with simultaneous carotid and coronary disease. We propose our technique as a bail-out trick in combined cases of CEA and CABG when the endarterectomy cannot be completed due to life threatening cardiac and hemodynamic instability.

\section{Consent}

Written informed consent was obtained from the patient for publication of this case report. A copy of the written consent is available for review by the Editor-in-Chief of this journal.

\section{Acknowledgements}

We would like to warmly thank Dr. Giannis Lazaridis for his valuable line drawings.

\section{Author details}

'Department of Vascular Surgery, Athens Medical Center, 5-7 Distomou St,

15125, Marousi Athens, Greece. ${ }^{2}$ Department of Cardiac Surgery, Athens

Medical Center, 5-7 Distomou St, 15125, Marousi Athens, Greece.

\section{Authors' contributions}

$J B, A G, M P$ came up with original conception and design. JB, AG, MP, NK, CK reviewed the medical literature, and were major contributors in writing the manuscript. NK, CK formatted the media. All authors read and approved the final manuscript

\section{Competing interests}

The authors declare that they have no competing interests.

Received: 23 October 2010 Accepted: 20 March 2011

Published: 20 March 2011

\section{References}

1. Gugulakis A, Kalodiki E, Nicolaides AN: Combined carotid endarterectomy and coronary artery bypass grafting. A literature review. Int Angiol 1991, 10:167-72.

2. D'Agostino RS, Svensson LG, Neumann DJ, Balkhy HH, Williamson WA, Shahian DM: Screening carotid ultrasonography and risk factors for stroke in coronary artery surgery patients. Ann Thorac Surg 1996, 62:1714-23.

3. John R, Choudhri AF, Weinberg AD, Ting W, Rose EA, Smith CR, Oz MC Multicenter review of preoperative risk factors for stroke after coronary artery bypass grafting. Ann Thorac Surg 2000, 69:30-5.

4. Imanaka K, Kato M, Ogiwara M, Kyo S: Active cerebral perfusion during carotid endarterectomy. Asian Cardiovasc Thorac Ann 2006, 14:e50-2.

5. Boysen G: Cerebral hemodynamics in carotid surgery. Acta Neurol Scand Suppl 1973, 52:3-86.

6. Mishra Y, Wasir H, Kohli V, Meharwal ZS, Malhotra R, Mehta Y, Trehan N: Concomitant carotid endarterectomy and coronary bypass surgery: outcome of on-pump and off-pump techniques. Ann Thorac Surg 2004, 78:2037-42.

7. Rao PV, Hosabettu PK, Dhaded S, Mathew A, Punnen J, Kanchi M: Distal carotid perfusion in combined carotid endarterectomy and OP-CABG. Asian Cardiovasc Thorac Ann 2007, 15:164-6.

doi:10.1186/1749-8090-6-33

Cite this article as: Bellos et al: Carotid shunt provides cerebral protection during emergency coronary artery bypass grafting in a patient with bilateral high grade carotid stenosis: a case report. Journal of Cardiothoracic Surgery 2011 6:33.

\section{Submit your next manuscript to BioMed Central and take full advantage of:}

- Convenient online submission

- Thorough peer review

- No space constraints or color figure charges

- Immediate publication on acceptance

- Inclusion in PubMed, CAS, Scopus and Google Scholar

- Research which is freely available for redistribution 